\title{
GM Distributed Generation Inverters in a Micro grid by Controlling Energy Management Using ANFIS
}

\author{
C.Lokanadham ${ }^{1}$ K.VijayaBhaskar ${ }^{2}$ L.Suresh ${ }^{3}$ \\ PG Student [EPS], Dept. of EEE, S.V.P.C.E.T, PUTTUR, ANDHRAPRADESH, India ${ }^{1}$ \\ Assistant professor, Dept. of EEE, S.V.P.C.E.T, PUTTUR, ANDHRAPRADESH, India ${ }^{2}$ \\ Assistant professor, Dept. of EEE, K.M.M.I.T.S,TIRUPATHI ANDHRAPRADESH, India ${ }^{3}$
}

\begin{abstract}
This project introduces a micro grid, which consists of different distributed generation units which are connected to the distribution grid. The operations of the DG units are coordinated by the power management algorithm in grid and islanded operations. The primary generation unit of the micro grid is the wind turbine and the proton exchange membrane fuel cell is used to supplement the variability in the power. In micro grid a battery is incorporated to overcome the difficulty of shortage of power demand during Islanded operation and to improve crest demands throughout grid connected operation. Previously the power management system was done using model predictive algorithm control design. Which has complex mathematical calculations to find out critical values Now in this project, ANFIS controller is used as the control design which reduces the design complexity as the logical operations are performed to find out critical values, the power quality such as harmonic compensation for nonlinear loads of the distribution system, will be improved when compared to model predictive algorithm control design and also It has fast response. The complete proposed system will be tested using MATLAB/SIMULINK and the simulation results reveal the attractive performance characteristics of the proposed system.
\end{abstract}

Keywords: Distributed generation (DG), power management, microgrid, adaptive neural interface system (ANFIS).

\section{Introduction}

In the near future, the demand for electric energy is expected to increase rapidly due to the global population growth and industrialization. This increase in the energy demand requires electric utilities to increase their generation. Recent studies predict that the world's net electricity generation is expected to rise from 17.3 trillion kilowatt-hours in 2005 to 24.4 trillion kilowatt-hours (an increase of $41 \%$ ) in 2015 and 33.3 trillion kilowatt-hours (an increase of 92.5\%) in 2030. Currently, a large share of electricity is generated from fossil fuels, especially coal due to its low prices. However, the increasing use of fossil fuels accounts for a significant portion of environmental pollution and greenhouse gas emissions, which are considered the main reason behind the global warming. For example, the emissions of carbon dioxide and mercury are expected to increase by 35\% and $8 \%$, respectively, by the year 2020 due to the expected increase in electricity generation. Moreover, possible depletion of fossil fuel reserves and unstable price of oil are two main concerns for industrialized countries. To overcome the problems associated with generation of electricity from fossil fuels, renewable energy sources can be participated in the energy mix. One of the renewable energy sources that can be used for this purpose is wind energy that is atmospheric air in motion. This wind energy can be converted to clean electricity through the turbine process. The use of wind turbine systems for electricity generation started in the seventies of the $20^{\text {th }}$ century and is currently growing rapidly worldwide.

To reduce the variability in the renewable sources, energy storage devices are used such as batteries and ultra capacitors. The inclusion of energy storage devices is also difficult for organizing demands and deviation in the load requirement. In present project, a micro grid composed of a Photovoltaic array (PV Array), PEMFC i.e., a proton-exchange membrane fuel cell, and storage battery (SB) is planned. PEMFC (a protonexchange membrane fuel cell) is employed as a backup generator unit to give back the power produced by the discontinuous nature of -Photovoltaic array. The Storage Battery is incorporated to overcome the difficulty of shortage of power demand during Islanded operation and to improve crest demands throughout grid connected operation. In micro grid to organize the distribution of power between different DG units an energymanagement algorithm is designed. The controller design proposed for the inverters of DG units is MPC Controller design. As The existing system consists of an MPC Controller in which the total harmonic distortion rate is high because its design complexity is high to find out critical values, so the power quality will be reduced. 


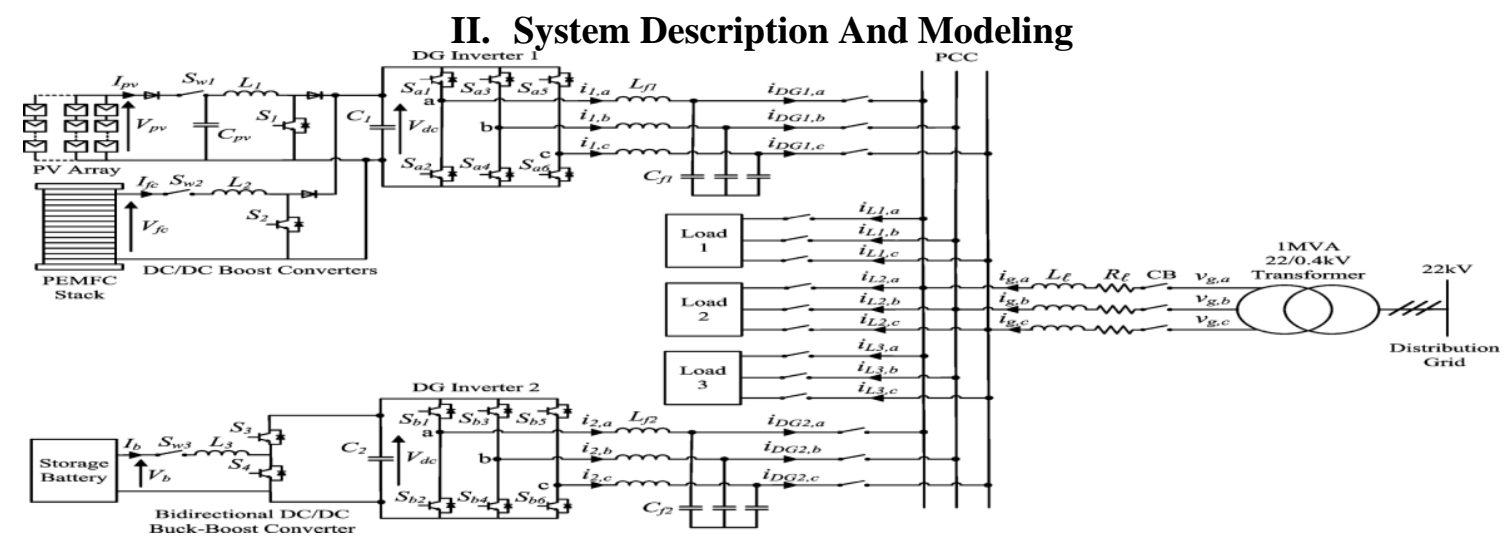

Fig 1.1: Overall configuration of the Existing micro grid architecture.

To reduce the variability in the renewable sources, energy storage devices are used such as batteries and ultra capacitors. The inclusion of energy storage devices is also difficult for organizing demands and deviation in the load requirement. In present project, a micro grid composed of a wind turbine, PEMFC i.e.,a proton-exchange membrane fuel cell, and storage battery (SB) is planned. PEMFC (a proton-exchange membrane fuel cell) is employed as an backup generator unit to give back the power produced by the discontinuous nature of wind turbine. The Storage Battery is incorporated to overcome the difficulty of shortage of power demand during Islanded operation and to improve crest demands throughout grid connected operation. In islanded operation, the function of the Storage Battery is to keep up the power stability in the micro grid which is given by

Where,

$$
\mathrm{P}_{\mathrm{DG}+} \mathrm{P}_{\mathrm{b}}=\mathrm{P}_{\mathrm{L}}
$$

$\mathrm{P}_{\mathrm{L}}$ is the real power delivered to the loads

$\mathrm{P}_{\mathrm{DG}}$ is the power delivered by the main DG unit

$\mathrm{P}_{\mathrm{b}}$ is the Storage Battery power

Storage Battery power which is subjected to the charging and discharging constraints given by

$\mathrm{P}_{\mathrm{b}}<=\mathrm{P}_{\mathrm{b}, \max }$

The energy limitation of the Storage Battery is determined based on the state-of-charge (SOC) limits which are given as

$$
\mathrm{SOC}_{\min }<\mathrm{SOC}<=\mathrm{SOC}_{\max }
$$

Even though the state-of-charge (SOC) of the battery cannot be calculated directly, it can be found by using many estimation methods.

During the micro grid operating in islanded operation from the distribution grid, the Storage Battery can operate in the charging, discharging, or idle mode depending on its State of charge (SOC) and power of storage battery $\mathrm{P}_{\mathrm{b}}$.

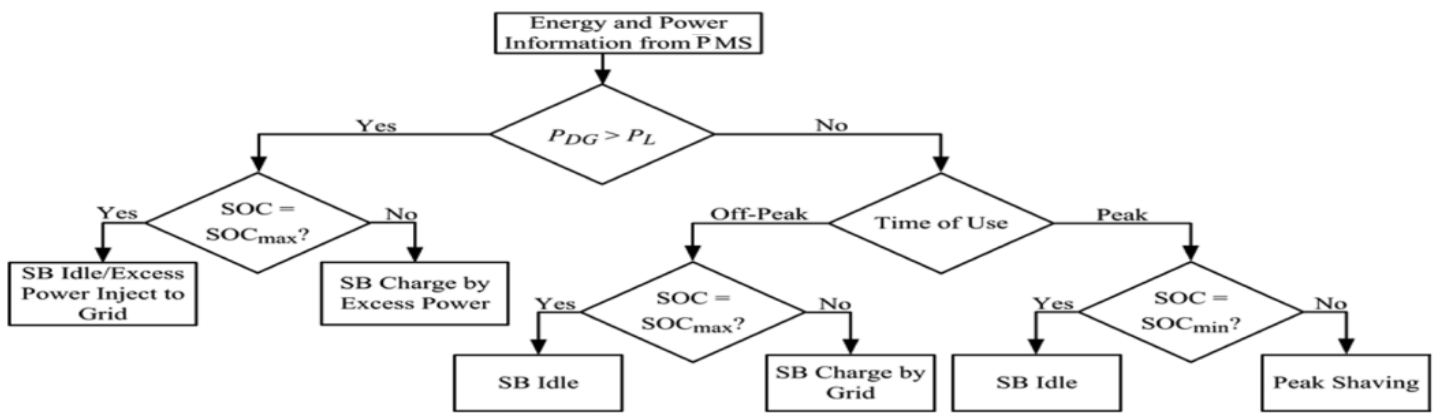

Fig 1.2. Operation of the SB during grid-connected operation.

In grid-connected function, the distribution grid is interfaced to the microgrid through a circuit breaker (CB) at the point of common coupling (PCC). The function of the main DG unit is to provide voltage and power for the loads therefore it reduces the burden of generation and delivery of power directly from the distribution grid. With the increasing of power-electronics devices being interfaced to the microgrid, the load currents might be unclear because of the presence of harmonic components. The purpose of DG units is also to compensate harmonics in the currents drawn by nonlinear loads in the microgrid, as a result that the harmonics will not spread to other electrical networks interfaced to the PCC. If the power produced by the main DG unit is higher than the total load demand in the microgrid, then the surplus power be able to charge the Storage Battery or 
GM Distributed Generation Inverters in a Micro grid by Controlling Energy Management Using ..

injected into the distribution grid, depending on the State of charge (SOC) of the Storage Battery, as shown in Fig. 2.1 Conversely, power produced by the main DG unit is less than the total load demand in the microgrid, the Storage Battery can be controlled to attain various energy-management functions depending on its State of charge (SOC) and the TOU (time of use) of electricity.

For the period of off-peak periods as shown in Fig. 2.1, when the cost of generation from the grid is low and if the State of charge (SOC) of Storage Battery is less than the maximum SOC limit SOCmax, the Storage Battery will be charged by the grid and the loads will be supplied by the main DG unit and the grid. In peak periods, when the cost of generation from the grid is high and if the Storage Battery State of charge is greater than the minimum SOC limit $\mathrm{SOC}_{\min }$, the Storage Battery can distribute power to the grid to attain peak sharing.

\section{Dg Inverter Modelling}

The switched voltage across the output of the $n$th DG inverter is represented by $u_{n} V_{d c n}$, where $u_{n}$ is the control input and $n=1,2$. The output side of the DG inverter is connected with an LC filter denoted by $\mathrm{C}_{\mathrm{fi}}$ and $\mathrm{L}_{\mathrm{fi}}$ to abolish the high switching frequency harmonics produced by the DG inverter. Fig 3.1 and 3.2 show the equivalent single-phase illustration of the DG inverters for islanded-connected and grid-connected operation.

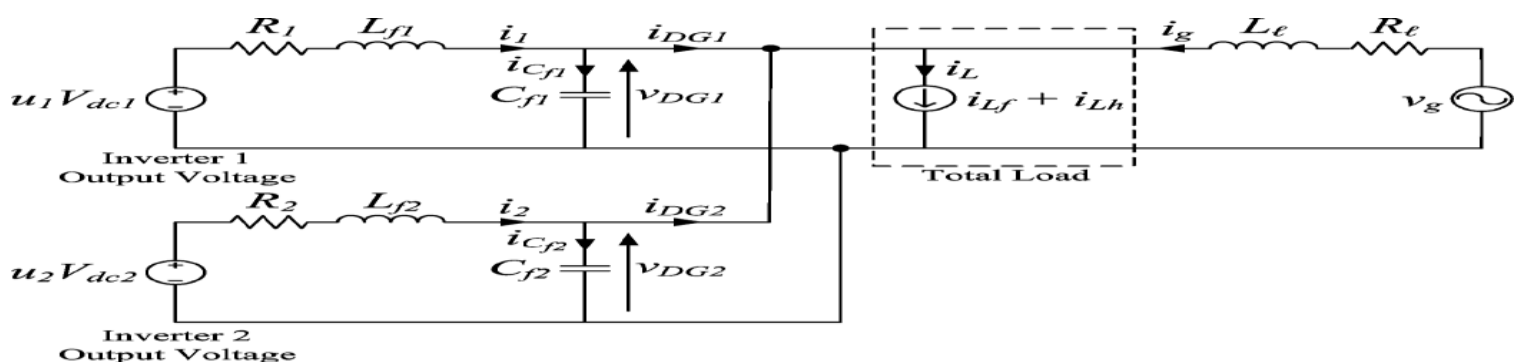

Fig. 2.1. Equivalent Diagram for single-phase of the DG inverters for grid connected operation.

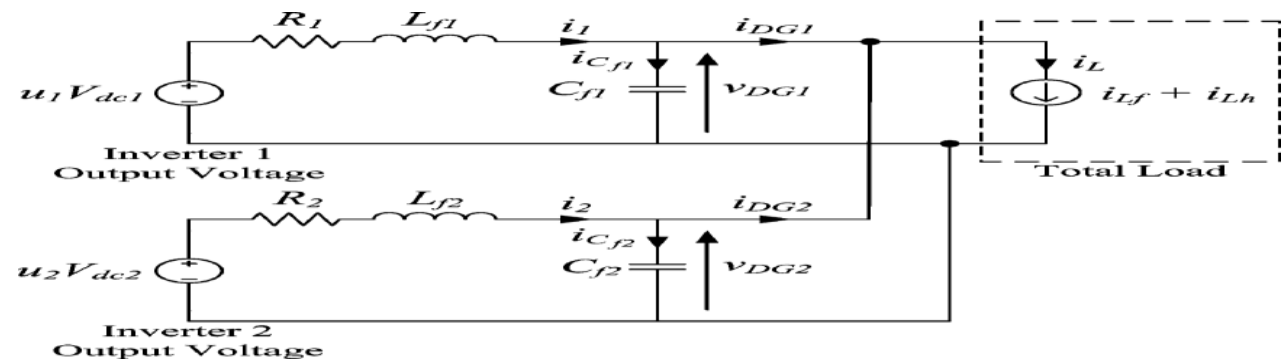

Fig. 2.2. Equivalent Diagram for single-phase of the DG inverters islanded operation.

The resistance $R_{j}$ reflects the loss of the DG inverter. Total load current $i_{L}$ is the summing of the currents given to the load $\mathrm{k}(\mathrm{k}=1,2,3)$, is represented by

$$
i_{L}=\sum_{k=1,2,3} i_{L k}=i_{L 1}+i_{L 2}+i_{L 3}
$$

where $\mathrm{i}_{\mathrm{g}}$ is the grid current. As shown in Fig.3.1, the utility substation supplies the voltage to a distribution grid represented by a voltage source $\mathrm{V}_{\mathrm{g}}$ during grid-connected operation, and is interfaced to the microgrid and to the loads through a distribution line with inductance $L_{l}$ and resistance $R_{L}$.

During the grid-connected operation, the grid voltage is identified and the microgrid shares the load requirement with the grid. Hence, to manage the power delivered to the loads, by using the CCM (current control mode) the DG inverter output current is controlled.

For the duration of islanded operation, the total load requirement will be supplied by microgrid as shown in Fig. 3.2 , and by using VCM (Voltage control mode) it is necessary that the output voltage can be regulated to a pure sine wave with a fixed magnitude.

To obtain a state-space model for the DG inverter through both grid-connected operation and islanded operations, Kirchhoff's current and voltage laws are applied to the current loop as shown in Fig. 3.3, 


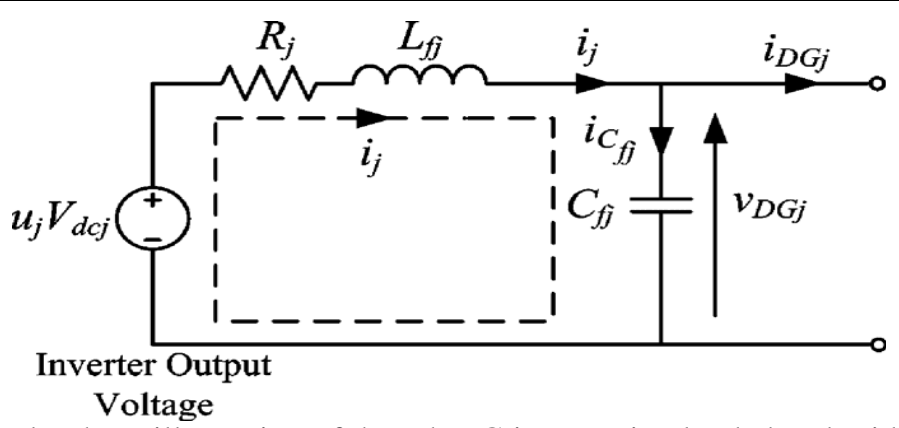

Fig 2.3. Single-phase illustration of the nth DG inverter inIslanded and grid-connected

$\frac{d i j}{d t}=-\frac{R j}{L f j} i j-\frac{1}{L f j} v D G j+\frac{V d c j}{L f j} u j$

operations.

$\frac{d v D G j}{d t}=\frac{1}{C f j} i j-\frac{1}{C f j} i D G_{j}$

where the subscripts $g$ and $j$ represent the model of DG inverter $j$ during grid-connected operation $(j=1,2,3)$ and $\mathrm{A}_{\mathrm{gj}}=A g j=-\frac{R j}{L f i} ; B g j 1=\left[\begin{array}{ll}-\frac{1}{L f j} & 0\end{array}\right] ;$

$B g j 2=\left[\frac{\text { Vdej }}{\text { Lfj }}\right]: C_{\mathrm{gj}}=1 ; \operatorname{Dgj} 1=[0-\mathrm{Cfj}] ; \quad \operatorname{Dgj} 2=0$

$\mathrm{Xgj}=\mathrm{i}_{\mathrm{j}}$ is the state $\left.; \mathrm{V}_{\mathrm{j}}{ }={ }_{\mathrm{vDGj}} \mathrm{d} v \mathrm{vDGj}_{\mathrm{dt}}\right]^{\mathrm{T}}$ is the exogenous input. $\mathrm{u}_{\mathrm{j}}$ is the control input, with $-1<=\mathrm{u}_{\mathrm{j}}<=1$; and $\mathrm{y}_{\mathrm{gj}}=\mathrm{i}_{\mathrm{DGj}}$ is the output.

\section{Introduction}

\section{ANFIS}

The idea of fuzzy logic and artificial neural network for organize problems has been grown in recent years. The motive is that the traditional control theory frequently requires a mathematical model for designing the controller. The inexactness of mathematical modeling generally degrades the performance of the controller, particularly for complex and nonlinear control problems. The introduction of the neural controllers and fuzzy logic controllers (FLC) based on multi layered neural networks has motivated new resources for the possible understanding of improved and high efficient control. In latest years, the combination between fuzzy logic and neural network that is fuzzy neural network (FNN) has been projected and developed. Generally the multiplexing of fuzzy logic and neural network is known as ANFIS (Adaptive Neuro Fuzzy Inference System). Neural system has numerous inputs and also has many outputs but the fuzzy logic has numerous inputs and only one output, so the integration of this two is know as ANFIS which is used for nonlinear applications.

\section{System Overview}

T-S fuzzy model was planned in1985 by Takagi and Sugeno .Later on it is known as Sugeno fuzzy model. It is a nonlinear model. Sugeno fuzzy model can appropriately state the dynamic characteristic of complex systems. in addition, Sugeno fuzzy model is the fuzzy inference model that is in the most common use. A usual fuzzy rule in this model has the following format:

If $l$ is $A$ and $m$ is $B$, Then $Z=f(l, m)$

Where $\mathrm{L} \& \mathrm{M}$ are fuzzy set antecedent, $\mathrm{Z}=\mathrm{f}(\mathrm{x}, \mathrm{y})$ is a crisp function in the Consequent.

Let us suppose the fuzzy inference system consist of two inputs $\mathrm{x}, \mathrm{y}$ with one output. If the rule base consists of two fuzzy if-then rules of Takagi and Sugeno's type then it is represented as given below:

$$
\begin{aligned}
& \text { Rule 1: Ifx is } A_{1} \text { andy is } B_{1} \text { Then } f_{1}=p_{1} x+q_{1} y+r_{1} \\
& \text { Rule 2: Ifx is } A_{2} \text { and y is } B_{2} \text { Then } f_{2}=p_{2} x+q_{2} y+r_{2}
\end{aligned}
$$

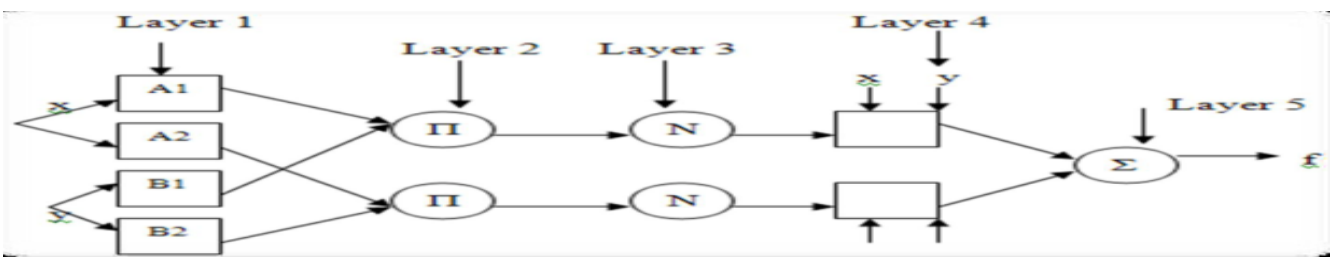

Fig 4.1: ANFIS structure for 2 -input variables for TSK Model 
GM Distributed Generation Inverters in a Micro grid by Controlling Energy Management Using ..

Layer 1: In this layer each node $\mathrm{i}$ is a square node with a node function where $\mathrm{x}$ is the input to node 0 , and $\mathrm{A}$ is the label related with this node function. In other words, $\mu$ is the membership function of A, and it determines the degree to which the given x satisfies the quantifier Ai. Gaussian Membership function is chosen with utmost equal to 1 and least equal to 0 . In this layer the Parameters are referred to as premise parameters. Membership functions are used for each of the input in this layer.

$$
\begin{aligned}
& O_{1, i}=\mu_{A_{i}}(x)=\exp \left[-\left(\frac{x-m_{i}}{\sigma_{i}}\right)^{2}\right] \text { for } \\
& O_{1, i}=\mu_{B_{i-2}}(x)=\exp \left[-\left(\frac{x-m_{i}}{\sigma_{i}}\right)^{2}\right] f o
\end{aligned}
$$

Layer 2: In this layer each node is a circle node labeled $\mathrm{H}$, which multiplies the incoming signals and sends the product out. For instance, each node output represents the firing strength of a rule.

$$
\mathrm{O}_{2, \mathrm{i}}=\mathrm{W}_{\mathrm{i}}=\mu_{\mathrm{Ai}^{*}} \mu_{\mathrm{Bi}} \text { for } \mathrm{i}=1,2
$$

Layer 3: In this layer each node is a circle node labeled $N$. The i-th node defines the ratio of the i-th rule's firing strength to the sum of all rules' firing strengths

$$
O_{3, i}=\bar{w}_{i}=\frac{w_{i}}{w_{1}+w_{2}} \text { for } i=1,2
$$

For convenience, outputs of this layer will be called normalized firing strengths.

Layer 4: In this layer each node $\mathrm{i}$ is a square node with a node function

$$
O_{4, i}=\bar{w}_{i} f_{i}=\bar{w}_{i}\left(p_{i} x+q_{i} y+r_{i}\right)
$$

Where $\bar{w}_{\bar{i}}$, is the output of layer 3 and $\{$ pi, qi, ri $\}$ is the set of parameters. In this layer the Parameters are referred to as consequent parameters.

Layer 5: In this layer the single node is a circle node labeled E that calculates the total output as the addition of all incoming signals, i.e.

\section{ANFIS Model}

$$
O_{5}=f=\sum_{i} \bar{w}_{i} f_{i}
$$

This is the block diagram of ANFIS Controller, ANFIS controller is the combination of neuralNetwork and Fuzzy Logic. Many inputs are applied to the neural network depending upon the inputs the neural network has some standard output, so depending upon the input and the output the neural network is trained, after training the neural network the output is applied to the fuzzy logic which generates the IF THEN rules and membership functions.

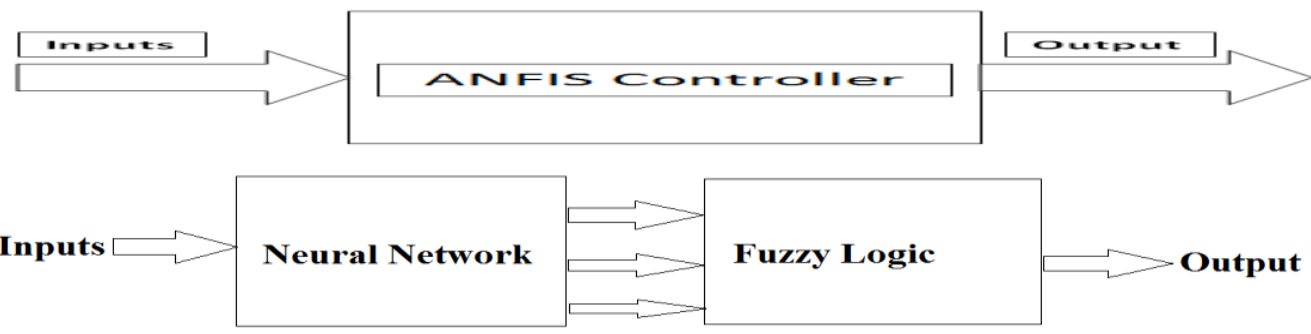

Fig 4.2: ANFIS MODEL

\section{Results And Discussion}

Test Case 1: Improvement of Quality of a power During Grid-Connected Operation

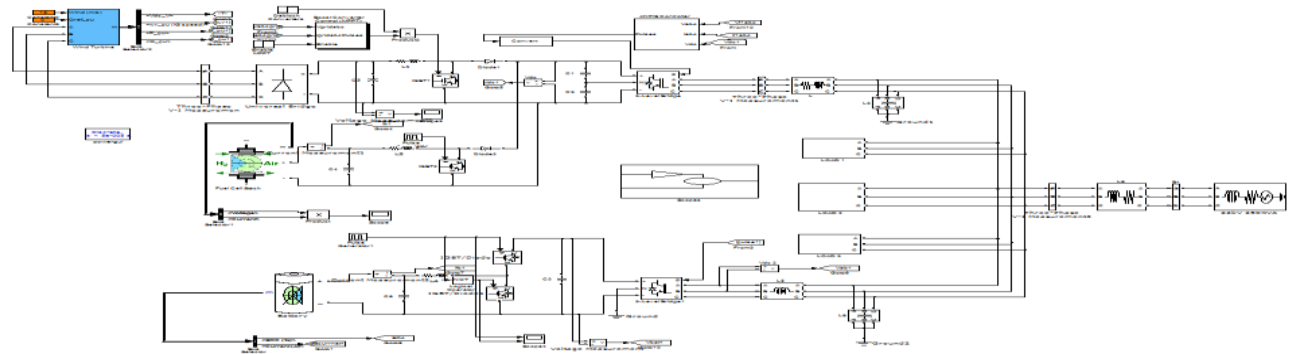

Fig 5.1: simulation Model during grid connected Operation 
GM Distributed Generation Inverters in a Micro grid by Controlling Energy Management Using ..

The first case shows the ability of the micro grid to enhance the power quality of the distribution network by compensating for the harmonics in the total load current $\mathrm{i}_{\mathrm{L}}$. As the nonlinear loads are interfaced to the distribution network, such that the harmonics will not spread to the rest of the distribution network in gridconnected operation. The Storage Battery is working in the charging mode to accumulate energy in off-peak period where the cost of generation from the grid is short to meet up future unexpected demands for power. The Storage Battery current $i_{b}$ and the SOC during charging for $0 \leq t<0.6 \mathrm{~s}$ are shown in Fig.5.6. The waveforms of the total load current $i_{L}$, the current given by the main DG unit $i_{D G}$ and grid current $i_{g}$ in this case are shown in Fig. 5.4. The per-phase currents $\mathrm{iL}_{1}, \mathrm{iL}_{2}$ and $\mathrm{iL}_{3}$ drawn by loads 1,2 , and 3 for $0 \leq \mathrm{t} \leq 0.6 \mathrm{~s}$ are shown in Fig. 5.5.

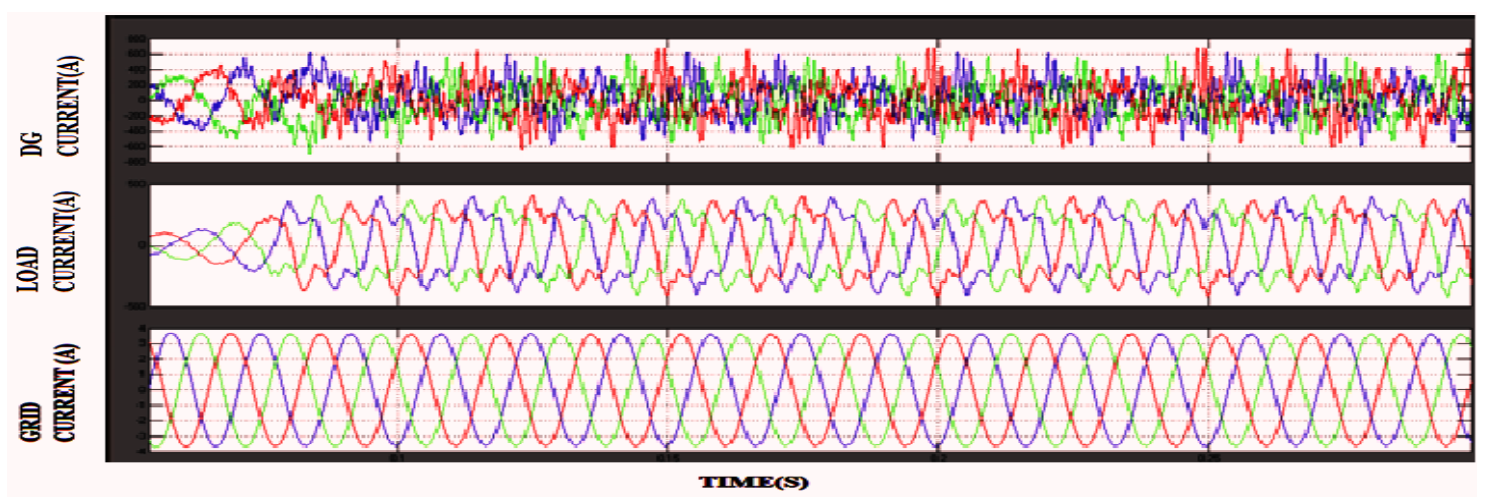

Fig. 5.2. Three-phase DG current $i_{D G}$ (top), load current $i_{L}$ (middle), and three-phase grid current $i_{g}$ (bottom) During Grid Connected Operation.
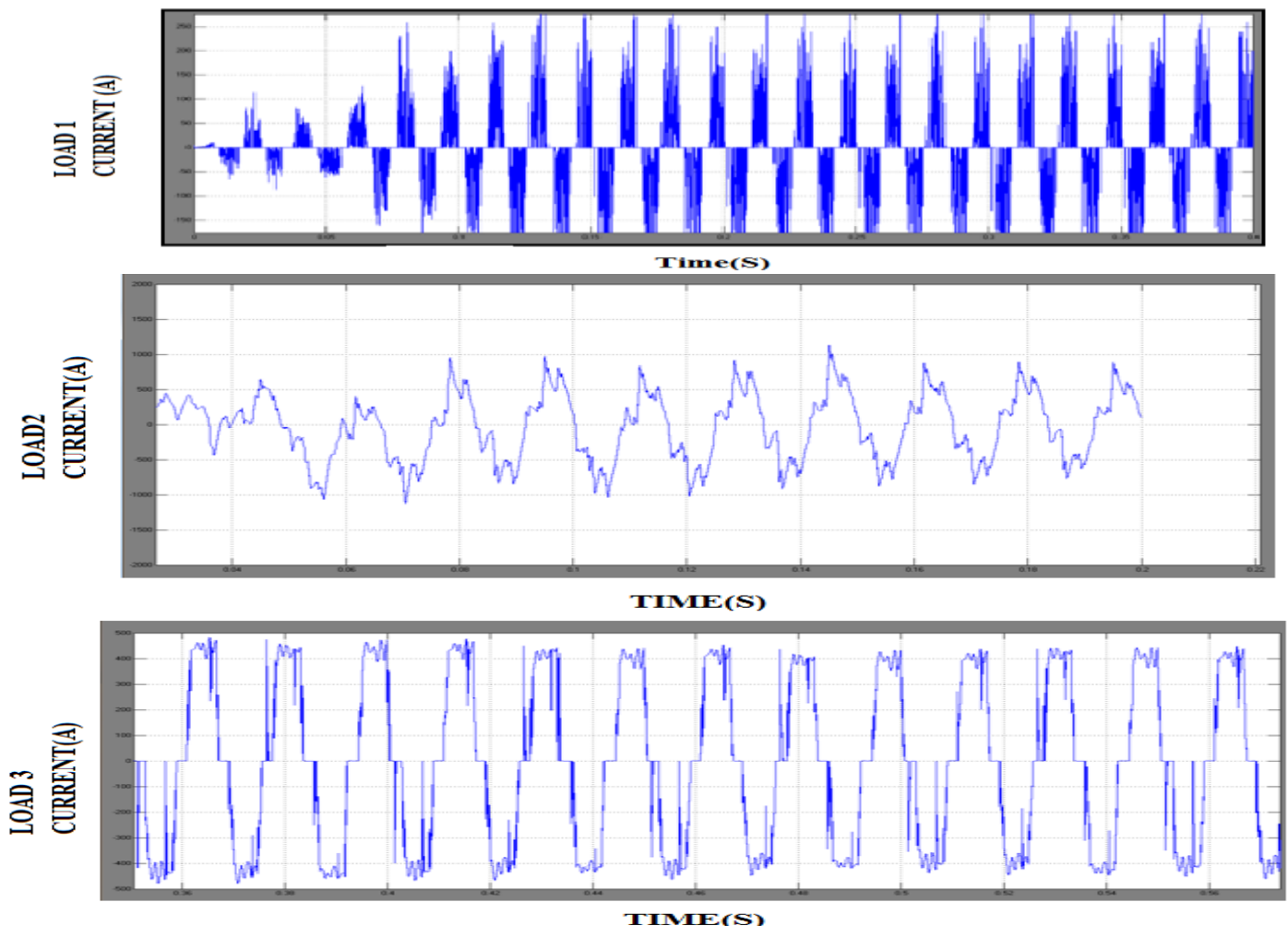

Fig.5.5. Per-phase currents drawn by loads 1, 2, and 3 During Grid Connected Operation.

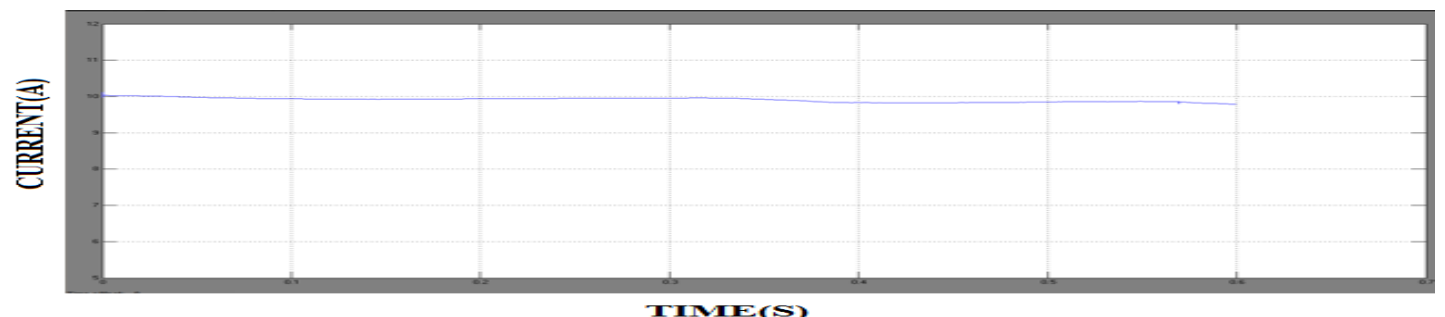

Fig.5.6: Waveform of the SB current during charging During Grid Connected Operation. 


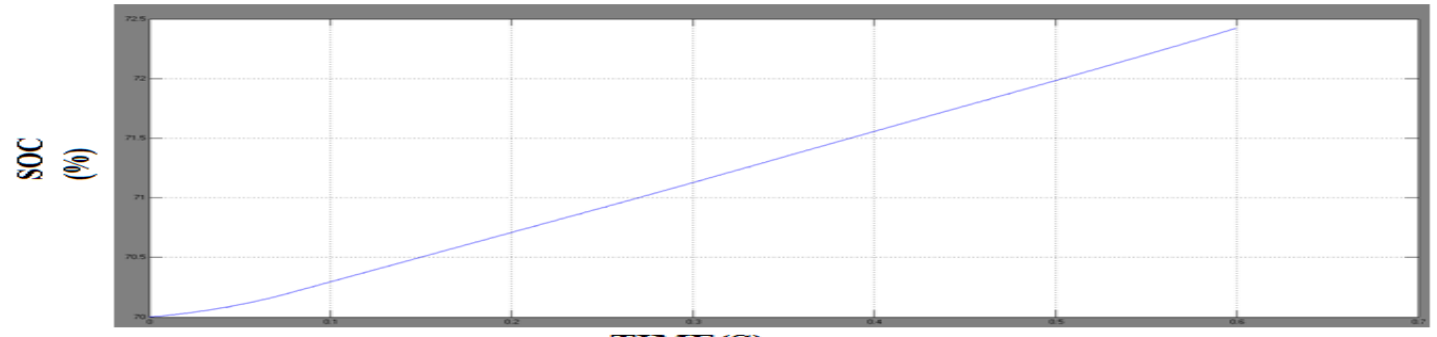

TIME(S)

Fig.5.7: SOC of the SB during charging in Grid Connected Operation.

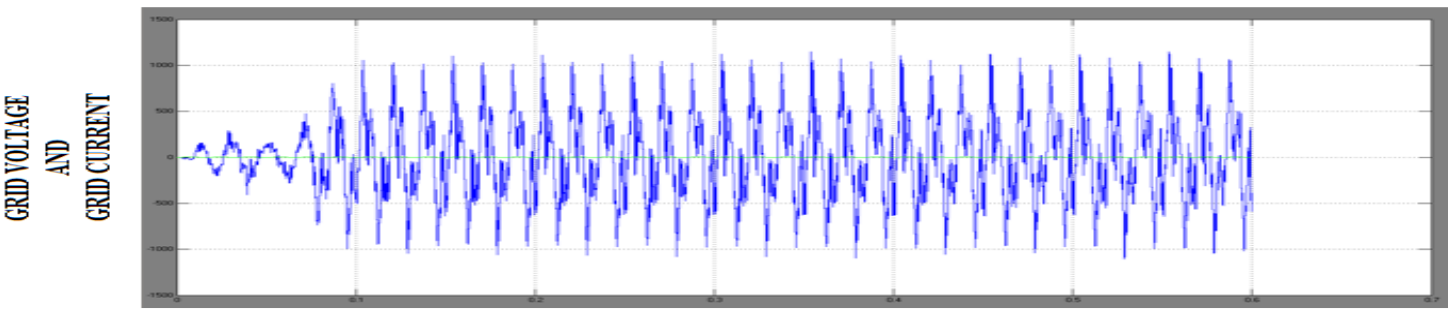

TIME(S)

Fig 5.8 : Wave forms of Grid Voltage and Current During Grid Connected Operation.

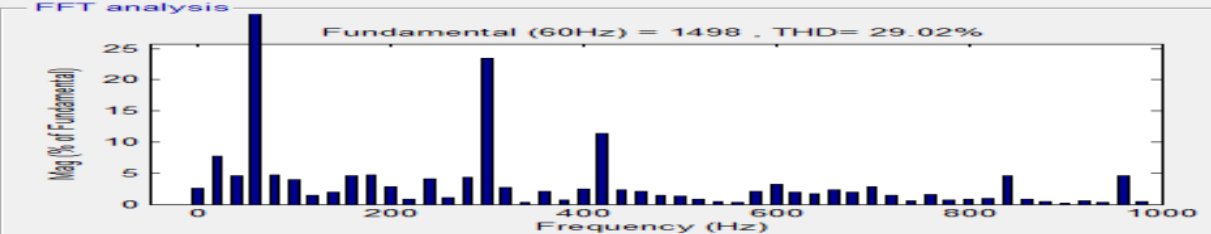

Fig 5.9: The total harmonic distortion (THD) value of load current $i_{L}$ using ANFIS

The total harmonic distortion (THD) value of load current $i_{L}$ is $29.02 \%$ as shown in Fig. 5.9. With the ANFIS controller THD value of is improved to about $14 \%$ when compared to previous methods (MPC Controller) as shown in fig.5.10

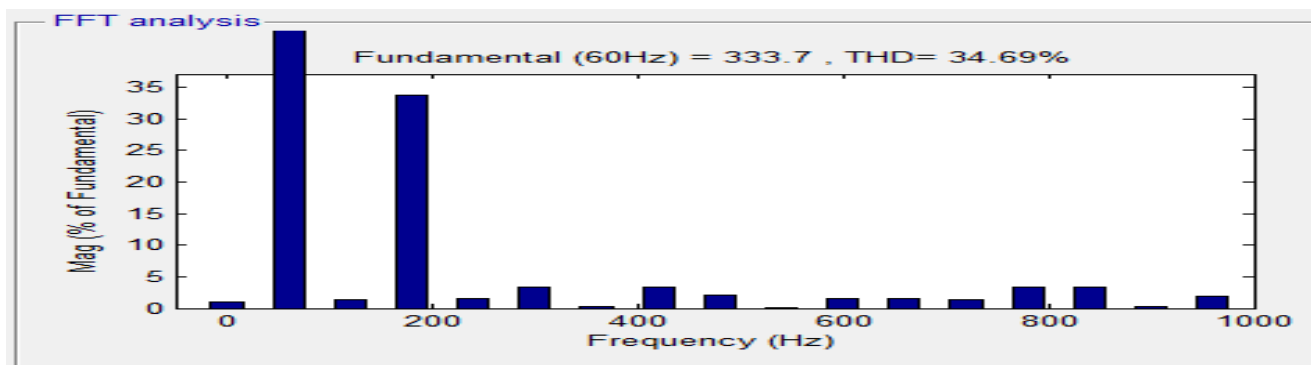

Fig 5.10 : The total harmonic distortion (THD) value of load current $i_{L}$ using MPC Controller

\section{Test Case 2: Load Shedding During Islanded Operation}

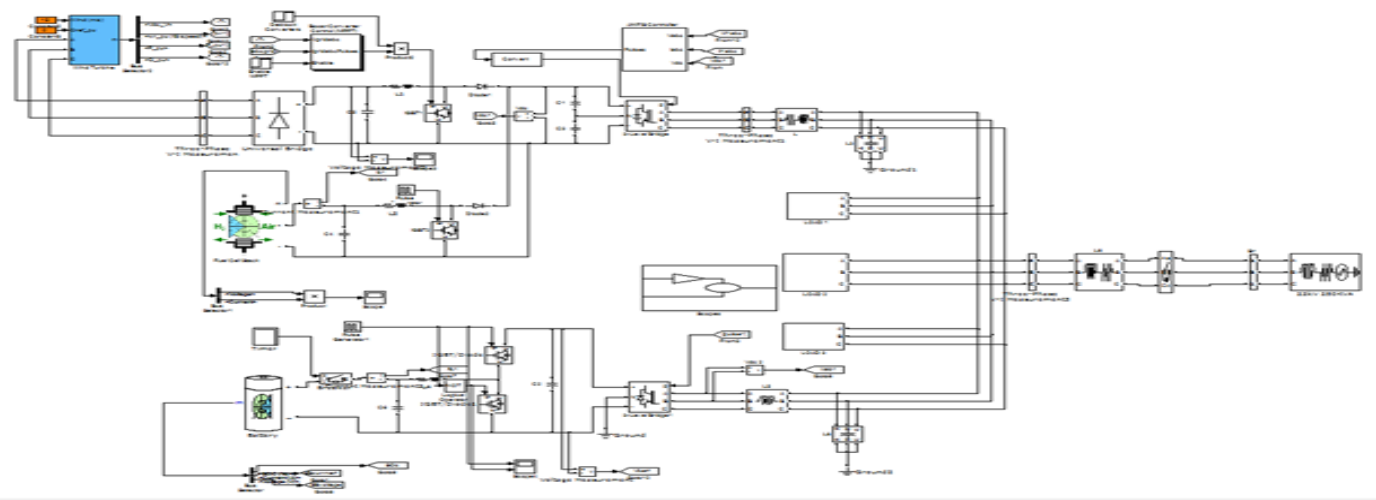

Fig 5.11: simulation Model during Islanded Operation 
In islanded operation, the total generation power of the micro grid may not be able to maintain its generation to meet up the power requirement of the loads. During such conditions, consumers will permit the non-critical load to be discarded so as to keep the constant function of the micro grid. The second test case shows the function of the microgrid which is islanded from the grid. In this case, the microgrid is primarily functioning in the grid-connected mode for $0 \leq \mathrm{t}<0.2 \mathrm{~s}$. The Storage Battery is primarily functioning in the idle mode and its State of charge is $80 \%$. As an error occurs on the network of the distribution grid, the Circuit Breaker function is to disconnect the microgrid from the distribution grid at $\mathrm{t}=0.2 \mathrm{~s}$.

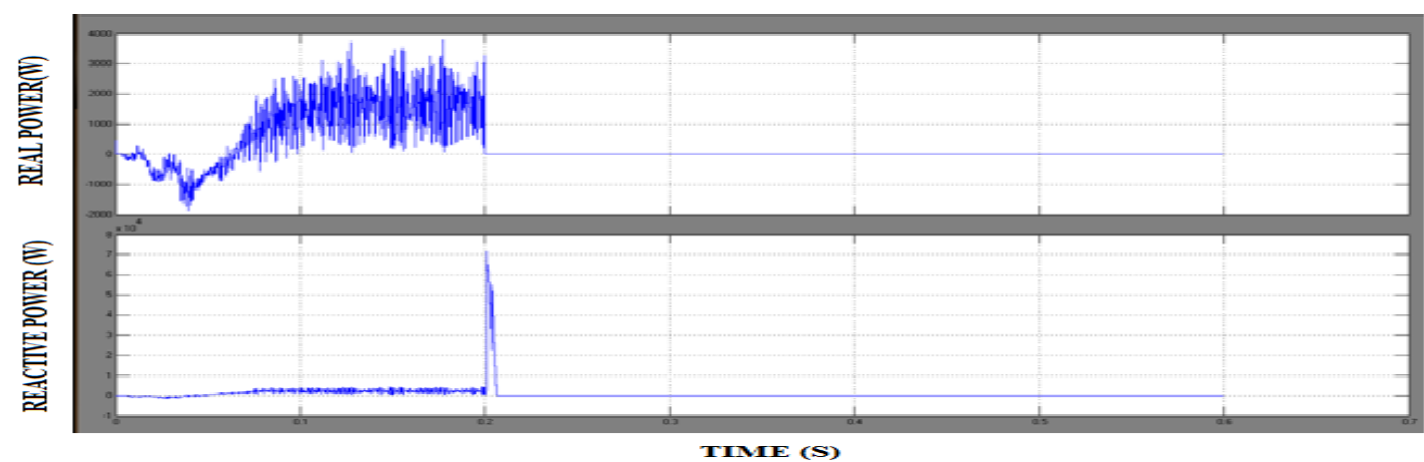

Fig. 5.12 the waveforms of the real and reactive power supplied by the grid.

The Circuit Breaker manages to separate the microgrid from the distribution grid, ensuing in zero real and reactive power delivered by the grid for $0.2 \leq \mathrm{t}<0.6 \mathrm{~s}$. The real power given by DG inverter 2 of the Storage Battery is shown in Fig. 5.12.

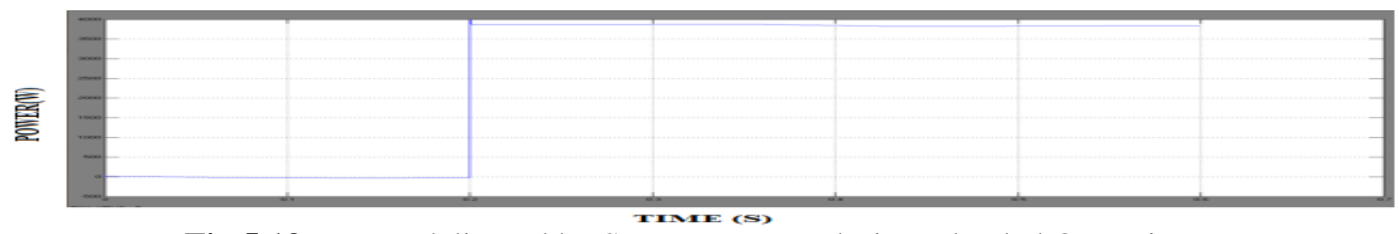

Fig 5.13: Power delivered by Storage Battery during Islanded Operation.

$0 \leq \mathrm{t}<0.2 \mathrm{~s}$, the Storage Battery is in the idle mode. After the beginning of the islanding operation at $\mathrm{t}=0.2 \mathrm{~s}$, the DG inverter 2 is tasked by the PMS to enhance its generation to offer real power of about $4 \mathrm{~kW}$ to the loads.

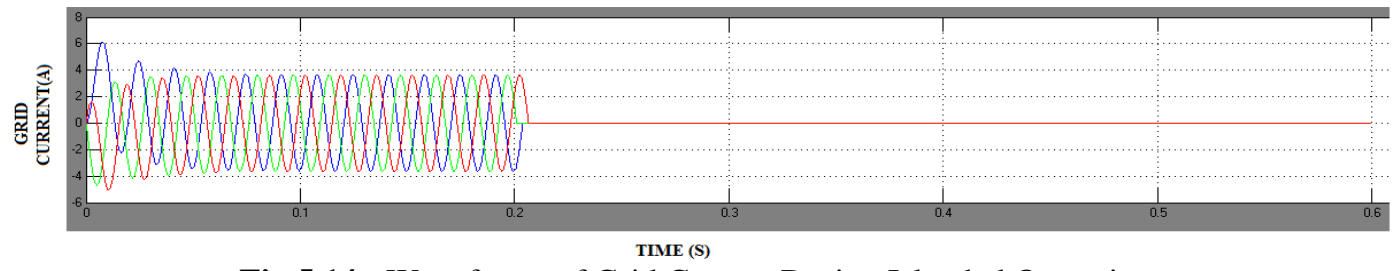

Fig 5.14 : Waveforms of Grid Current During Islanded Operation

Fig 5.14 shows the grid current during islanded operation in which the grid current is supplied to the loads till $0.2 \mathrm{~s}$ then between $0.2 \leq \mathrm{t}<0.6 \mathrm{~s}$ the current reduces to 0 because the grid will get disconnected and it is operated in Islanded operation

\section{Conclusion And Future Scope}

Conclusion: In this Thesis, an Adaptive Neuro fuzzy Interface control system coordinates the operation of multiple DG inverters in a micro grid for grid-connected and islanded operations has been presented. The proposed controller for the DG inverters is predicated on an incipiently developed ANFIS in order to reduce the overall computation time. The control design is to extract the harmonic spectra of the load currents and to engender the compulsory references for the controller. The DG inverters can compensate for load harmonic currents in a homogeneous way as conventional compensators, such as active and passive filters, and, hence, no adscititious equipment is required for power-quality amelioration. To realize the perspicacious grid concept, an assortment of Power-management functions, such as peak shaving and load shedding, have additionally been demonstrated in the simulation studies. The results have validated that the micro grid is able to handle different operating conditions efficaciously during grid-connected and islanded operations, thus incrementing the overall reliability and stability of the micro grid.

DOI: $10.9790 / 1676-120201104112 \quad$ www.iosrjournals.org $\quad 111 \mid$ Page


The entire proposed system will be tested using MATLAB/SIMULINK and the simulation results demonstrate the attractive performance characteristics of the proposed system.

Future Scope: The proposed controller i.e. ANFIS for the DG inverters is utilized rudimentary Pulse width Modulation technique, it can reduces the higher order harmonics only, that can be elongated to Current Control loop so that, we can reduce the lower order harmonics also.

\section{References}

[1]. S.Braithwait,"Behaviormanagement,"IEEE Power and Energy Mag., vol. 8, no. 3, pp. 36-45, May/Jun. 2010.

[2]. N. Jenkins, J. Ekanayake, and G. Strbac, Distributed Generation. London, U.K.: IET, 2009.

[3]. M. Y. Zhai, "Transmission characteristics of low-voltage distribution networks in China under the smart grids environment," IEEE Trans. Power Del., vol. 26, no. 1, pp. 173-180, Jan. 2011.

[4]. G. C. Heffner, C. A. Goldman, and M. M. Moezzi, "Innovative ap- proaches to verifying demand response of water heater load control," IEEE Trans. Power Del., vol. 21, no. 1, pp. 1538-1551, Jan. 2006.

[5]. R. Lasseter, J. Eto, B. Schenkman, J. Stevens, H. Vollkommer, D. Klapp, E. Linton, H. Hurtado, and J. Roy, “Certs microgrid laboratory test bed, and smart loads," IEEE Trans. Power Del., vol. 26, no. 1, pp. 325-332, Jan. 2011.

[6]. A. Molderink, V. Bakker, M. G. C. Bosman, J. L. Hurink, and G. J. M. Smit, "Management and control of domestic smart grid technology," IEEE Trans. Smart Grid, vol. 1, no. 2, pp. 109-119, Sep. 2010

[7]. A. Mohsenian-Rad, V. W. S. Wong, J. Jatskevich, R. Schober, and A. Leon-Garcia, “Autonomousdemandsidemanagementbasedongame- theoretic energy consumption scheduling for the future smart grid," IEEE Trans. Smart Grid, vol. 1, no. 3, pp. 320-331, Dec. 2010. 